\title{
Cidadania participatória no cotidiano \\ escolar: a vez e a voz das crianças e dos jovens
}

\section{Participatory citizenship in the daily life of schools: the voice and turn of children and young people ${ }^{1}$}

\author{
Isabel Menezes ${ }^{2}$ \\ Pedro Ferreira ${ }^{2}$
}

\begin{abstract}
RESUMO
Ao longo dos últimos 60 anos, a Europa tem vivido vagas de transição democrática que envolveram profundas mudanças políticas e uma forte ênfase no papel da Educação na promoção de uma cidadania democrática e europeia. No entanto, e apesar do seu passado autoritário, Portugal tem assistido a uma forte inconsistência das políticas educativas nesta área, em que momentos de grande ênfase na promoção da cidadania vão se alternando com momentos em que o foco é colocado em competências nas disciplinas "básicas". No entanto, é escassa a investigação sobre o impacto destas mudanças no cotidiano das escolas. Numa pesquisa sobre educação para a cidadania, realizamos um estudo junto de alunos de escolas portuguesas envolvidos na construção de perfis comunitários sobre a democracia e a participação no passado, no presente e no futuro. O perfil comunitário envolve um processo de investigação participativa em que os alunos recolhem - através de análise documental, entrevistas ou questionários - e analisam dados sobre as oportunidades de exercício da cidadania, no passado e no presente, e refletem sobre as possibilidades que se abrem no futuro. Os alunos revelaram um grande envolvimento neste processo cujo impacto é analisado
\end{abstract}

DOI: $10.1590 / 0104-4060.36586$

$1 \mathrm{O}$ artigo decorre do projeto EduCiParT (ref. PTDC/CPE-CED/102952/2008) financiado por Fundos FEDER através do Programa Operacional Factores de Competitividade - COMPETE e por Fundos Nacionais através da FCT - Fundação para a Ciência e a Tecnologia.

2 Universidade do Porto. Porto, Portugal. Centro de Investigação e Intervenção Educativas. Rua Alfredo Allen, 4200-135. 
a partir dos seus discursos e dos seus professores. O estudo revela como a aprendizagem da cidadania pode manter-se como espaço de resistência às políticas educativas no cotidiano das escolas.

Palavras chave: educação para a cidadania; perfil comunitário; democracia; participação.

\begin{abstract}
During the last 60 years, Europe has faced a series of democratization processes that have generated profound social and political transformations and a strong emphasis on the role of education in promoting a European and democratic citizenship. However, and in spite of its authoritarian past, Portugal has witnessed a strong inconsistency of educational policies in this domain, with moments of intense emphasis on encouraging citizenship that are followed by periods of complete devaluation with a 'back to the basics' approach. However, there is almost no research on the impact of these changes in the daily life of schools. This paper describes a research that involved Portuguese pupils in the construction of community profiles in the past, present and future of democracy and participation. Community profiling involves pupils in a participatory research process in which they collect - through document analysis, interviews, or questionnaires - and analyze data on opportunities for citizenship, now and in the past, and they reflect over possible evolutions in the future. The analysis of the process and its impacts on pupils is based on interviews with teachers and pupils, suggesting a strong commitment. The research also reveals how citizenship learning can be a space for resisting education policies in the daily life of schools.
\end{abstract}

Keywords: citizenship education; community profiling; learning democracy; participation.

\title{
Introdução
}

A história da Europa ao longo do século XX é, em boa medida, uma história de democratização, com vagas de transição para a democracia que incluem - como em Portugal - revoluções ou - como é o caso de Espanha - formas mais difusas de transformação social (HUNTINGTON, 1992). Não é por isso surpreendente que as clássicas preocupações com o papel da escola na formação democrática dos alunos (DEWEY, 1916; BENEVIDES, 1996) se tenham reavivado desde meados da década de 1990 (OSLER; STARKEY, 2006), levando 
Pablo Gentili (2000, p. 143) a considerar a educação para a cidadania um "legado fundamental" do século XX. A Europa vivia, por essa altura, uma série relevante de transformações: a queda do muro de Berlim e a transição para a democracia dos países do então designado "bloco soviético", com a consequente unificação da Alemanha, a guerra dos Balcãs, a instituição da União Europeia como entidade de governação transnacional, e a emergência de sinais de desconfiança e distanciamento face à política e de um aumento da xenofobia e intolerância em vários países (RIBEIRO et al., 2012). A crescente ênfase no papel da escola na promoção de uma cidadania, democrática e europeia, foi o motto para várias reformas educativas na Europa, traduzindo-se numa afirmação da educação para a cidadania como objetivo central da educação escolar (MENEZES,1999, 2003; NÓVOA, 1996) - papel análogo ao que, na própria Europa, a escola já havia desempenhado durante a instituição do Estado Nação, quando foi um veículo da "criação" de identidades nacionais (HABERMAS, 1995).

A evolução portuguesa foi acompanhando esta tendência, mas com particularidades relevantes. A primeira prende-se com o papel da escola durante a ditadura (1926-1974), instrumento para a promoção de sujeitos passivos e obedientes à lei, respeitadores da trilogia "Deus, Pátria e Família", dentro de um contexto de rigoroso controlo social (AZEVEDO; MENEZES, 2008; MÓNICA, 1978; STOER, 1986). Ora, e obviamente, a revolução democrática de 1974 trouxe novas formas de conceber o papel dos cidadãos e de promover o seu envolvimento político, mas as iniciativas experimentadas logo no período revolucionário (1974-76) foram ulteriormente abandonadas por riscos de inculcação ideológica (BREDERO DE SANTOS, 1995). As responsabilidades da escola no domínio da capacitação cívica e política dos cidadãos eram claramente valorizadas e a experiência da ditadura gerava uma resistência a práticas que corressem o risco de ser tendenciosas e doutrinadoras. Foi apenas após a estabilização democrática e a entrada de Portugal, em 1985, na então Comunidade Económica Europeia (a precursora da atual União Europeia) que a Lei de Bases do Sistema Educativo reafirmou a capacitação cidadã como objetivo da educação (MENEZES, 1999). No entanto, a concretização deste objetivo tem sido marcada por profundas ambivalências por parte dos decisores políticos: a Reforma do sistema educativo de 1986 optou por criar uma disciplina (de Desenvolvimento Pessoal e Social) que nunca se viria a implantar no terreno por falta de formação de professores; a Reorganização Curricular de 2001 propôs espaços curriculares (Formação Cívica e Área de Projecto) que podiam ser assegurados por qualquer professor (MENEZES, 2003), mas o atual Ministro da Educação suspendeu esta medida, sem qualquer avaliação, porque entendeu ser mais importante investir nas disciplinas "fundamentais" de Matemática e Língua Portuguesa. Ou seja, e embora a investigação sugira que há uma débil 
cultura política e uma distância ao poder acentuada (VILLAVERDE CABRAL, 2007), para além de um fraco conhecimento dos jovens sobre o passado político (MENEZES et al., 2005), a educação para a cidadania parece nunca ter passado de uma prioridade retórica sem impacto relevante no cotidiano das escolas e dos alunos - situação que não é, aliás, exclusiva de Portugal, mas se tem verificado em países como o Reino Unido, a Espanha ou a França (BENEDICTO, 2006; FAULKS, 2006; RUGET, 2006).

\section{Da cidadania prescrita à cidadania em construção}

Estes movimentos contraditórios de renovada ênfase na educação para a cidadania, rapidamente seguida de desinvestimento, reacenderam debates e levaram a desenvolvimentos interessantes. Encontramos, por exemplo, críticas ao modo como tantas vezes a educação para a cidadania acaba neutralizada e despolitizada em práticas escolarizadas que se recusam a olhar para o que está para além dos muros da escola (FERREIRA et al., 2013; FRAZER, 2007; MCCOWAN, 2009; MONTEIRO; FERREIRA, 2011; RUGET, 2006). E há ainda a proposta de que se mude o foco do ensino para a aprendizagem da cidadania (BIESTA; LAWY, 2006; BIESTA, 2011). Enfatizar a aprendizagem, e neste caso a aprendizagem situada, é também reconhecer que ela se faz, muitas vezes e de várias formas, para além da escola, nos contextos de vida dos/as jovens e nas suas interações quotidianas (MENEZES, 2010). Desta forma é possível ligar esta proposta às tradições que têm vindo a defender visões da educação nas quais a aprendizagem é vista como um processo ativo, intencional e que cria significado (ROGOFF et al., 2003), em que o aprendido é construído a partir da experiência e "depende da situação e contexto em que tem lugar" (TERHART, 2003, p. 31). Ora, se a aprendizagem é um "processo de transformação da participação em actividades culturais continuadas" (ROGOFF et al., 2003, p. 182), a aprendizagem da cidadania será um processo de transformação da participação em atividades, práticas e interações nas quais a dimensão política da vida dos/as jovens ganha saliência. Passa assim a ser fundamental dar atenção "aos diferentes modos em que os/as jovens 'aprendem a democracia' através da sua participação em contextos e práticas que compõem a sua vida quotidiana, na escola, universidade, e na sociedade em geral" (BIESTA, 2011, p. 6).

É claro que os contextos da vida do dia a dia, e os conflitos que pontuam a experiência cotidiana, são relevantes quando se consideram as oportunidades para se aprender a cidadania assim como para se compreender o que ela pode 
ser (FERREIRA; AZEVEDO; MENEZES, 2012). Esta mudança de foco - do ensino de uma cidadania prescrita para a aprendizagem de uma cidadania em construção - traz consigo também a valorização da dimensão processual na qual o resultado final não se reporta já a uma noção fixa de cidadania, ou a um modo preestabelecido de agir como ou ser cidadão/cidadã, mas a uma noção contingente na qual o próprio entendimento da cidadania acaba problematizado (GENTILI, 2000). Mais do que um resultado de uma certa aprendizagem escolar em que se preparam jovens para serem futuros cidadãos responsáveis, ativos e competentes, importa compreender a cidadania (também a dos/as jovens) como uma prática que existe no contexto das ordens culturais, sociais, políticas e económicas e as oportunidades que eles têm para agir na sua cidadania, ser cidadania, e assim aprender, não se podendo portanto ignorar aquelas que são as suas "condições de cidadania"(BIESTA; LAWY, 2006).

Ora, o que se ensina sobre a cidadania nos esforços educativos com esse fim acabará sempre tendo de ser confrontado com estas outras aprendizagens. Não ignorar isto deve levar-nos a criar oportunidades que "facilitem o exame crítico daquelas que são as condições da cidadania das pessoas jovens, mesmo se isso os/as levar a concluir que a sua cidadania é limitada e restringida" (BIESTA, 2011, p. 16). Ora, a estratégia do perfil comunitário, tal como foi utilizada neste trabalho, pode ser útil para a aprendizagem da cidadania pelo modo como enfatiza a dimensão processual, ativa e problematizadora no envolvimento dos/ as jovens com o exame dos seus contextos de vida enquanto desafia as "condições de cidadania" dos jovens criando formas de participação nos contextos com potencial reflexivo e politizador.

Enquanto estratégia, o perfil comunitário vem da prática da intervenção comunitária em que tem sido frequentemente utilizado no levantamento de recursos e necessidades de intervenção através do "envolvimento ativo da própria comunidade" (FRANCESCATO; TOMAI; GHIRELLI, 2002; HAWTIN; HUGHES; PERCY-SMITH, 1998, p. 5). Tendo definições, práticas de utilização e contextos de aplicação que vão variando, o perfil comunitário pode ser visto como uma forma de "documentar o conhecimento contextual de uma comunidade", que é centrado na própria comunidade (LOVE et al., 2007, p. 179). Porque envolve as pessoas dos contextos e comunidades na construção de diferentes perfis (o que implica a sua participação nos processos de recolha, análise e discussão dos dados) - territorial, demográfico, económico, de serviços, institucional, antropológico, psicológico e futuro (FRANCESCATO, 2000; GELLI; MANNARINI; BONIFAZI, 2004) - cria oportunidades para re-conhecerem os seus contextos de vida e se re-conhecerem enquanto participantes destes de uma forma colaborativa, negociada e ativa, podendo desta forma gerar condições para uma aprendizagem de cidadania com potencial emancipatório (MENEZES, 
2010). Isto será tanto mais possível quanto mais se recusar a ideia de que o processo de construção dos perfis procura descrever a comunidade que existe como algo estável e prévio ao próprio processo e se afirmar que o processo de construção dos perfis abre espaço a práticas reflexivas nas quais o envolvimento conjunto pode levar a novas conexões e formas de compreender a comunidade e em que "mais do que um 'perfil', a aprendizagem é o resultado" (LOVE et al., 2007, p. 186).

A literatura é ainda clara relativamente ao modo como esta estratégia se tem revelado útil na intervenção com jovens (CICOGNANI, 2014; FRANCESCATO; TOMAI; GHIRELLI, 2002; TEATE; BALDWIN, 2009) pelo que se justifica que seja tida em conta quando a intenção é a de se criarem oportunidades com potencial educacional e transformador das questões da cidadania. Adicionalmente, inspirados pelas experiências italianas em que se propõe a construção de perfis do "futuro" (FRANCESCATO, 2000), e tendo em conta os objetivos do projeto, decidimos propor a construção de três perfis temporais: um perfil do passado no qual o foco se colocou nas experiências anteriores à revolução do 25 de abril de 1974; um perfil centrado no presente e nas questões atuais; e um perfil do futuro no qual se pudessem explorar as perspectivas dos jovens sobre como estariam essas questões daí a 35-40 anos. O potencial emancipatório da estratégia é ainda reforçado pelo modo como permite aos/às jovens ter liderança no processo de construção do seu próprio conhecimento e criar oportunidades significativas para a tomada de perspectiva e aumento da sua sensibilidade relativamente à situação de outros (por exemplo, criando uma compreensão diferente daquela que era a vida dos seus pais enquanto alunos) e de participação (KELLETT, 2010).

\section{O desenho da pesquisa: perfil comunitário do passado, presente e futuro da democracia}

A pesquisa "Educação para a cidadania participatória em sociedades em transição", com financiamento da Fundação para a Ciência e Tecnologia, visou aprofundar a compreensão sobre a forma como o passado autoritário é reconhecido nas políticas educativas, nos currículos e nas práticas das escolas em países europeus que viveram uma transição recente para a democracia, e como este reconhecimento interfere com a promoção de uma cultura cívica que valoriza a participação ativa e crítica dos cidadãos. A pesquisa envolvia três fases: na primeira procedemos à análise das políticas educativas europeias no campo da 
educação para a cidadania; na segunda centramo-nos na análise das formas como os manuais de História e de Educação para a Cidadania analisam e discutem o passado ditatorial e a transição para a democracia em Portugal e Espanha; na terceira, que é objeto deste artigo, envolvemos professores e alunos de quatro escolas públicas na construção de perfis comunitários do passado (antes da revolução do 25 de abril), presente e futuro da democracia.

A pesquisa envolveu quatro estudos de caso intensivos, entre janeiro e junho de 2012, em escolas públicas localizadas em diferentes zonas geográficas e com características socioeconómicas diversas, que tinham em comum uma história de colaborações anteriores com a Universidade do Porto. O trabalho realizado pelos professores e alunos foi acompanhado por três investigadoras ${ }^{3}$, bolseiras do projeto, que monitorizaram o processo através de observação participante, registos, vídeo e entrevistas.

A escola 1 é do ensino fundamental ( $1^{\circ}$ ao $4^{\circ}$ ano de escolaridade), localizada num bairro social com grande privação socioeconómica e diversidade étnica; a escola 2 é também do ensino fundamental $\left(5^{\circ}\right.$ ao $9^{\circ}$ ano de escolaridade), situada numa zona rural, com alguma diversidade socioeconómica; a escola 3 é uma escola do ensino fundamental e médio ( $7^{\circ}$ ao $12^{\circ}$ ano de escolaridade), de uma zona central da cidade do Porto, com uma população diversa do ponto de vista socioeconómico, com instalações recentemente melhoradas e que é especialmente reconhecida pelos muito bons resultados dos seus alunos nos exames de acesso ao ensino superior; e a escola 4 é também uma escola do ensino fundamental e médio de uma zona central da cidade do Porto, mas com instalações degradadas e que tem perdido alunos - sendo uma antiga escola industrial tem investido em cursos do ensino tecnológico e profissional. A Tabela 1 apresenta uma caracterização das crianças e jovens em cada escola. Como se pode observar, as escolas e os professores selecionaram as disciplinas ou espaços curriculares que mais se adequavam ao tema do projeto, havendo uma grande diversidade.

Em cada turma, por iniciativa dos professores e alunos, foram constituídos grupos que escolheram temas relacionados com os direitos de cidadania e as oportunidades de participação na escola e na comunidade antes do 25 de abril, hoje em dia e no futuro. Em alguns casos, houve preocupação em articular os temas com os conteúdos disciplinares (e.g., pobreza, acesso à saúde e educação, a crise do estado social, etc.), noutros a opção foi deixada aos interesses dos alunos (e.g., os estilos de vida na comunidade cigana, o papel das mulheres, etc.). O perfil comunitário assenta num processo de pesquisa participativa cen-

3 Ana Bela Ribeiro, Andreia Caetano e Mariana Rodrigues, que são atualmente estudantes do programa doutoral em Ciências da Educação da Universidade do Porto. 
TABELA 1 - IDENTIFICAÇÃO DAS ESCOLAS E DOS GRUPOS DE ALUNOS PARTICIPANTES

\begin{tabular}{l|l|l|l}
\hline Escolas & $\begin{array}{l}\text { Ano de } \\
\text { Escolaridade }\end{array}$ & $\begin{array}{l}\text { Disciplinas e espaços } \\
\text { curriculares envolvidos }\end{array}$ & Participantes \\
\hline Escola 1 & $3 .^{\circ}$ ano & Formação Cívica & $\begin{array}{l}13 \text { crianças (6 raparigas e 7 rapazes) na } \\
\text { sua maioria de etnia cigana }\end{array}$ \\
\hline Escola 2 & $6 .^{\circ}$ ano & $\begin{array}{l}\text { Educação Moral e } \\
\text { Religiosa }\end{array}$ & 25 jovens (11 raparigas e 14 rapazes) \\
\cline { 2 - 4 } & $8 .^{\circ}$ ano & $\begin{array}{l}\text { História e Formação } \\
\text { Cívica }\end{array}$ & 18 jovens (7 raparigas e 11 rapazes) \\
\hline Escola 3 & $12^{\circ}$ ano & Geografia & 16 jovens (10 raparigas e 6 rapazes) \\
\hline Escola 4 & $10^{\circ}$ ano & $\begin{array}{l}\text { Área de Integração } \\
\text { (ensino profissional) }\end{array}$ & 12 jovens (7 raparigas e 5 rapazes) \\
\cline { 2 - 4 } & $11^{\circ}$ ano & 11 jovens (3 raparigas e 6 rapazes) \\
\hline
\end{tabular}

FONTE: Dados sistematizados pelos autores.

trado no passado e no presente: os alunos, com o apoio das investigadoras e dos professores, identificaram fontes de onde puderam recolher dados (e.g., livros, enciclopédias, jornais, entre outros), potenciais respondentes (e.g., familiares, profissionais, académicos e outros elementos relevantes da comunidade) e instrumentos de recolha de dados (e.g., entrevistas, questionários e respetivos guiões). Depois, envolveram-se em processos de pesquisa que incluíram a análise documental (off- e online), a realização de entrevistas com informantes privilegiados ou de rua; noutros casos, houve a aplicação de inquéritos por questionário e, noutros ainda, a recolha de registos fotográficos da sua comunidade, etc. Embora o processo tenha sido acompanhado pelas investigadoras, que apoiaram a construção de instrumentos de observação, a preparação da recolha dos dados e, num momento posterior, a concretização dos procedimentos de análise dos dados (análise de conteúdo e estatística descritiva), houve a preocupação de garantir o protagonismo dos alunos. Ou seja, a construção do perfil implicou um processo de formação dos alunos enquanto investigadores (KELLET, 2010) que tentou promover o seu "empoderamento epistemológico", como diria Penny Oldfather (1995, p. 132), não apenas porque aprenderam a planear e executar uma pesquisa, como porque tiveram oportunidades de refletir sobre os resultados, considerando potenciais evoluções no futuro, bem como de apresentar e discutir os seus resultados e reflexões com outros investigadores. Efetivamente, os resultados deste trabalho de pesquisa foram apresentados em cada turma/ escola e num seminário na universidade em que os grupos apresentaram a sua investigação em formato de póster e discutiram as suas conclusões com investigadores do Centro de Pesquisa em Educação (CIIE). Por exemplo, alguns 
grupos analisaram a evolução do papel das mulheres na sociedade portuguesa, analisando estatísticas e inquéritos a nível nacional, mas também realizando entrevistas com as suas próprias mães. Constataram que a revolução do 25 de Abril de 1974 resultou num forte reconhecimento dos direitos das mulheres, com um grande aumento do emprego feminino, mas também de direitos de cidadania, como votar; as mulheres vivem hoje uma situação de total igualdade de direitos que os jovens consideraram ser irreversíveis no futuro. O grupo dos alunos mais novos apresentou o safari fotográfico da sua comunidade, um bairro social do Porto, acompanhado por música por si composta e interpretada ao vivo. Estes trabalhos foram comentados por dois professores da universidade, especialistas em investigação-ação e em história contemporânea, e pelos professores participantes das várias escolas.

\section{O impacto do processo de pesquisa no cotidiano escolar}

Para explorar o potencial impacto do perfil comunitário como metodologia de aprendizagem da cidadania foram realizadas entrevistas com os professores e alunos das turmas participantes ao longo e no final do processo. Todas as entrevistas foram transcritas e analisadas através de análise temática (BRAUN; CLARKE, 2006). Os nomes que acompanham os excertos são fictícios.

Embora reconhecendo que as escolas desenvolvem educação para a cidadania, seja nas aulas ou nas atividades co-curriculares, muitas das quais em ligação com a comunidade, os professores destacam como as mudanças recentes nas políticas curriculares - por exemplo, a extinção da Área de Projeto que se tinha concretizado nesse ano letivo - têm afetado o tempo dedicado a estas questões: "nós podíamos trabalhar muitas temáticas e que acabavam por dar uma continuidade à Formação Cívica [...] em que se podia trabalhar, fazer pesquisas, encontrarem um projeto e depois intervir no meio [...]" (professora Luísa), para além de permitir uma "entreajuda entre os professores" e um enriquecimento das competências dos alunos: "o saber trabalhar em grupo, comunicar, pesquisar, organizar-se e responsabilizar-se" (professora Joana). Mas, apesar destas mudanças políticas, algumas escolas continuam a valorizar esta dimensão da formação dos alunos, "apelando à participação dos alunos em variadas atividades da escola, desde do Conselho Geral à Associação de Estudantes [Grémio], ao desenvolvimento de projetos" (Joana). No entanto, o professor Francisco reconhece que se houvesse mais escolas a promover a participação dos alunos "teríamos ganhos a todos os níveis, não só ligados à cidadania $[\ldots]$ porque 
aproximávamos a escola da vida, da vida concreta", especialmente porque os jovens são bastante críticos da qualidade da vida democrática no nosso País e acabam por revelar um desinteresse por estas questões porque desacreditam da possibilidade de mudança, embora participem através de modos característicos da sua geração: “'batalhas' de rua que envolvem a dança, música, rap e o breakdance". Luísa considera também que os múltiplos mandatos que as políticas curriculares impõem às escolas resultam numa ausência de aprofundamento: "tratamos de tudo e às vezes perguntamos: 'afinal do que é que nós tratamos?'”, considerando que as opções da política educativa atual, justificadas pela redução de despesas com a educação, resultam num risco:

Há [...] escolhas pedagógicas [...] não sei se vão poupar com algumas medidas que estão a tomar... os custos, no futuro, serão bem maiores, não em termos económicos, mas a outros níveis, a nível pedagógico, da educação integral, nos alunos (Luísa).

A experiência de implementação do perfil comunitário foi positivamente avaliada por todos os professores, muito embora reconhecendo as dificuldades do processo no que diz respeito ao pouco tempo disponível e às dificuldades na colaboração de entidades exteriores à escola. No entanto, foi vista pelos alunos mais novos "como um projeto à parte $[\ldots]$ foram momentos que lhes demos para eles falarem da vida deles, das inquietações que eles sentiam" (professor Roberto), para além da oportunidade de apresentar o seu trabalho na universidade: o "fato de terem podido brilhar perante pessoas que eles não conhecem de lado algum [...] não houve um deles que tenha dito que não tivesse gostado". Para além do envolvimento dos alunos ("durante o fim de semana recebia uma chuva de e-mails"), a importância do seminário final foi também realçada por Luísa porque "nunca foram ao Porto porque os pais não têm carro, é um meio muito carente $[. .$. ] nunca tinham conhecido nem visto [uma universidade] tudo aquilo que envolveu este projeto foi uma descoberta!". O processo parece, ainda, ter favorecido a participação ativa de todos os alunos, criando condições para aprendizagens relevantes:

Todos tiveram lugar para participar [...] víamos que há sempre aqueles alunos mais lideres e que dinamizam, mas eu acho que eles gostaram de tudo, mesmo até do próprio tema, de escolher o tema, fazer o guião de entrevista, de encontrar as questões e corrigir as questões... [até] 
manusear o gravador [...] [ganharam] consciência crítica em relação a algumas questões [...], que eles nem sabiam que podiam intervir e ter pensamentos autónomos sobre aquilo. (Luísa)

Também para a professora Mariana foi importante os alunos tomarem contacto com a realidade, saírem da escola e irem "para o campo e ter que adequar, às vezes, o guião [...] à entrevista, como ela estava a decorrer, e essa capacidade de eles terem de adequar o que tinham à entrevista" e terem tido a oportunidade de comprovar, por eles próprios, "o que estava escrito na bibliografia que consultaram, nos sítios que consultaram, afinal aquilo era mesmo uma realidade", para além da oportunidade de tornarem público o seu trabalho no seminário final. Joana destaca também o desenvolvimento de várias competências, "contacto com os outros, a capacidade de organização, a capacidade de pesquisa, o desenvolvimento de competências para a apresentação", realçando que "ao ter um carácter prático, ao contactar diretamente com a realidade, tem muito mais efeito do que alguma coisa que seja por ouvir dizer". Francisco também sublinha o entusiamo dos alunos, especialmente à medida que o processo vai avançando:

O princípio da liberdade do aluno poder escolher é interessante, o princípio de que ele ia fazendo uma investigação e o produto final era uma coisa que ele quisesse, que não precisava de ser necessariamente uma ou outra coisa [...] o aluno sente que pode escolher, que pode decidir [...] no final do processo há uma compreensão completamente diferente do que é que afinal andámos aqui a fazer neste tempo, nestes dois ou três meses de trabalho em conjunto [...] chegam ao fim todos contentes e dizem: "Viu professor, nós conseguimos... estava sempre a dizer que nós não íamos fazer [...] (Francisco)

Na opinião dos alunos a experiência de construção do perfil foi positiva, pois existe uma carência de oportunidades e condições para a discussão e debate no contexto escolar: "normalmente nós ficamos apenas com a opinião do professor e não podemos discutir em conjunto, quer tenhamos opiniões semelhantes ou não [...] não há tempo para mais!" (Ricardo). Diogo lembra, tal como os professores, a eliminação da Área de Projecto do currículo: “o Ministério da Educação acabou com esta área onde podíamos realizar este tipo de projetos [...] não era um 'trabalho da escola' que leva um dia a fazer e a entregar, era um projeto que leva tempo e que nos enriquece mais do que um trabalho de 'copy-paste"'. 
Ora, como afirma Elvira, "neste tipo de metodologia, temos de ser autónomos e [...] guiar o nosso próprio trabalho", o que, na opinião de João, "enriquece a nossa formação, a nossa cultura e promove o nosso poder crítico". As oportunidades de interação com a comunidade são igualmente valorizadas por Sofia, que considera: "quando vamos para a rua e perguntamos à comunidade, enriquecemos o nosso trabalho porque compreendemos o que está a acontecer lá fora, fora da escola". Mas a experiência de interação tem também implicações negativas: Rita queixa-se: "fomos a um centro de saúde e entregamos uma carta a pedir para fazer um trabalho, explicamos que era urgente e, até agora, não tivemos resposta". No entanto, Eduardo sublinha que desta forma os alunos aprendem a "ser importantes na sociedade. Ter uma opinião e tornar a nossa opinião ouvida", enquanto Marta sublinha, tal como os professores, a saliência de atravessar os muros da escola:

Há uma diferença entre fazer um trabalho que é visto e avaliado apenas pelo professor, e fazer um trabalho que vai ser visto e avaliado pelo professor, mas também partilhado com pessoas fora da escola, que nos podem dar novos insights e informação. (Marta)

\section{Considerações finais}

As políticas educativas têm vacilado na ênfase à educação para a cidadania, entre a centralidade e a irrelevância, em Portugal como noutros países europeus, sugerindo que existe uma forte ambivalência na forma como os decisores políticos veem o papel da escola na capacitação cívica e política dos cidadãos. A nossa pesquisa mostra, no entanto, como o cotidiano das escolas pode ser um espaço de resistência às políticas educativas, permitindo a sobrevivência de espaços de aprendizagem da cidadania. A implementação dos perfis comunitários nestas quatro escolas, pesando embora os constrangimentos de falta de tempo e espaços curriculares, mostra como uma oportunidade para as crianças e jovens experimentarem o papel de investigadores sobre temas da cidadania, com ênfase no "mundo real" para além dos muros da escola, pode ser uma experiência que permite que aos alunos aprendam "sobre a sua própria posição enquanto cidadãos" (BIESTA, 2008, p. 4).

Os dados recolhidos através da observação do processo e das entrevistas aos professores envolvidos mostram como os alunos aprofundaram as suas 
competências de comunicação, de pesquisa e de trabalho em equipa, mas também a capacidade de analisar criticamente os direitos e deveres de cidadania, no passado, presente e futuro, permitindo, como afirma a professora Mariana,

A confrontação dos alunos com realidades que, por vezes, eles não conhecem; tiveram a oportunidade de pensar, refletir e realizar juizos críticos sobre diferentes questões [...] como foram tratados no passado, como são compreendidos no presente e como perspetivam o futuro. (Mariana)

Ora, o perfil comunitário permitiu valorizar e aprofundar a agência dos alunos, potenciando o conhecimento do real que resultou do seu próprio trabalho de pesquisa, e afirmando o seu direito a construir uma visão pessoal e crítica sobre os direitos de cidadania e as oportunidades de participação no passado, no presente e no futuro. Mas também permitiu considerar e valorizar as especificidades do seu cotidiano e a forma como vivem - o diário de uma das investigadoras regista este momento, no safari fotográfico do bairro da periferia:

Neste dia realizámos um safari fotográfico com os alunos pelo bairro [...] Digamos que o que aconteceu foi uma espécie de visita guiada pela comunidade e, de vez em quando, tiravam umas fotografias. Mostraram-nos uma igreja, o campo de jogos, a associação cultural e recreativa, mas os rapazes estavam mesmo empenhados em levar-nos ao sítio onde passam grande parte do tempo livre, ou seja, o local onde passam grande parte das suas vidas, quando não estão na escola. Este sítio ficava debaixo da ponte [...], um local protegido da eventual chuva. Neste sítio os jovens, apenas os rapazes porque as raparigas não vêm para aqui, montaram uma tenda com plásticos e paus, limparam a vegetação existente no chão. Pelo que me parece, estes jovens sentiram necessidade de ter um espaço onde pudessem estar a brincar, conviver livremente [...] Julgo esta necessidade de os jovens procurarem/criarem um espaço para puderem se reunir é um indicador da carência ou inexistência de espaços/recursos disponíveis na comunidade para ocupação e dinamização dos tempos livres dos mais jovens. (RODRIGUES, 2012, p. 17).

Uma primeira constatação que emerge deste projeto é que, como diria Dewey (1916), a vida é a fonte central de aprendizagem sobre a cidadania. Faz pouco sentido pensar-se que é possível promover a participação dos/as jovens 
sem se criarem as condições para desenvolverem as suas perspectivas sobre o mundo que os/as rodeia e afirmar a necessidade de serem mais do que meros/ meras espectadores/as (CICOGNANI, 2014) e não é possível levar isto a cabo sem envolver os/as jovens numa reflexão (com outros) sobre o cotidiano nos seus contextos de vida, o presente da sua história e a mudança da sua comunidade.

A segunda constatação é que, apesar das políticas educativas, se podem criar condições para o empoderamento dos atores escolares (professores e alunos) se forem criadas oportunidades para "reflectirem criticamente e articularem politicamente as suas necessidades, exigências e juízos" (HEDKE, 2013, p. 55). A pesquisa permitiu reconhecer que "a cidadania é sempre um processo em construção... [dando oportunidades para os] indivíduos tornarem-se protagonistas de 'sua' própria cidadania" (GENTILI, 2000, p. 148) e que, apesar das orientações da política educativa, a escola pode ser um espaço de participação praticada (LIMA, 2001), "um sítio onde se ganha o gosto pela política, isto é, onde se vive a democracia, se aprende a ser intolerante com as injustiças e a exercer o direito à palavra" (CANÁRIO, 2005, p. 88). A consequência deste reconhecimento é que a intervenção educativa que tenha a aprendizagem da cidadania como objetivo é, ela própria, um projeto politicamente comprometido: porque cria condições para a expressão e escuta da voz dos participantes, capacitando-os enquanto atores ativos e valorizando a diversidade de formas em que essa voz se pode expressar, porque encoraja a expressão de dissensões e pluralismo, e porque afirma o direito dos alunos e dos professores a tomarem decisões e exercerem poder sobre a suas próprias vidas na escola, reconhecendo que, para além das oscilações das políticas educativas, a vivência e o aprofundamento da democracia são tarefas inevitáveis no cotidiano escolar.

\section{REFERÊNCIAS}

AZEVEDO, C.; MENEZES, I. Transition to democracy and citizenship education in Portugal: changes and continuities in the curricula and in adolescents' opportunities of participation. Journal of Social Sciences Education, v. 9, n. 1, p. 131-148, 2008.

BENEDICTO, J. La construcción de la ciudadanía democrática en España (1977-2004): de la institucionalización a las prácticas. Revista Española De Investigaciones Sociológicas, v. 114, n. 6, p. 103-136, 2006.

BENEVIDES, M. V. M. Educação para a democracia. Lua Nova, n. 38, p. 223-237, 1996. 
BIESTA, G. J. J. A school for citizens: civic learning and democratic action in the learning democracy. In: LINGARD, B.; NIXON, J.; RANSON, S. Transforming learning in schools and communities. London: Continuum, 2008, p. 170-183.

BIESTA, G. J. J. Learning democracy in school and society: education, lifelong learning and the politics of citizenship. Rotterdam: Sense Publishers, 2011.

BIESTA, G.; LAWY, R. From teaching citizenship to learning democracy: overcoming individualism in research, policy and practice. Cambridge Journal of Education, v. 36, n. 1, p. 63-79, 2006.

BRAUN, V.; CLARKE, V. Using thematic analysis in psychology. Qualitative Research in Psychology, v. 3, p. 77-101, 2006.

BREDERODE SANTOS, M. E. Os aprendizes de pigmaleão. Lisboa: Ed. Instituto de Estudos para o Desenvolvimento, 1995.

CANÁRIO, R. O que é a escola? Um “olhar” sociológico. Porto: Porto Editora, 2005.

CICOGNANI, E. A. "Lost" youth generation ? Reflections from a community assessment study in Italy. Baskent University Journal of Education, v. 1, n. 1, p. 112-122, 2014.

DEWEY, J. Democracy and education. New York: The Macmillan Company, 1916.

EHMAYER, C.; REINFELDT, S.; GTOTTER, S. Agenda 21 as a concept for sustainable development. Paper presented at III Panel of Experts, Vienna, May 12, 2000.

FAULKS, K. Rethinking citizenship education in England: some lessons from contemporary social and political theory. Education, Citizenship and Social Justice, v. 1, n. 2, p. 123-140, 2006.

FERREIRA, P. D.; AZEVEDO, C. N.; MENEZES, I. The developmental quality of participation experiences: beyond the rhetoric that "participation is always good!" Journal of Adolescence, v. 35, n. 3, p. 599-610, 2012.

FERREIRA, P. D.; CAETANO, A.; RODRIGUES, M.; LOPES, C. C.; PAIS, S. C.; ARAÚJO, H. C.; MENEZES, I. Visions of the authoritarian past in citizenship education policies and practices in Spain and Portugal. In: HEDKE, R.; ZIMENKOVA, T. Education for civic and political participation: a critical approach. Londres: Routledge, 2013. p. 207-224.

FRANCESCATO, D. Community psychology intervention strategies as tools to enhance participation in projects promoting sustainable development and quality of life. In: Proceedings of the Euroconference "Quality of Live - Sustainability - Environmental Changes". Austria: Austrian Research Centres, 2000. p. 35-45.

FRANCESCATO, D.; TOMAI, M.; GHIRELLI, G. Fondamenti di psicologia di comunitá: principi, strumenti, ambiti di applicazione. Roma: Carocci, 2002.

FRAZER, E. Depoliticising citizenship. British Journal of Educational Studies, v. 55, n. 3, p. 249-263, 2007. 
GELLI, B.; MANNARINI, T.; BONIFAZI, A. The meanings of community: sense of place and participation. In: SÁNCHEZ-VIDAL, A.; ZAMBRANO, A.; PALACÍN, M. European community psychology: community, power, ethics and values. Barcelona: Publicacions Universitat de Barcelona, 2004. p. 230-261.

GENTILI, P. Qual educação para qual cidadania? Reflexões sobre a formação do sujeito democrático. In: AZEVEDO, J. C.; GENTILI, P.; KRUG, A.; SIMÓN, C. Utopia e democracia na educação cidadã. Porto Alegre: Editora da Universidade/UFRGS, 2000. p. 143-156.

HABERMAS, J. O Estado-Nação europeu frente aos desafios da globalização. Novos Estudos Cebrap, n. 43, p. 87-101, 1995.

HAWTIN, M.; HUGHES, G.; PERCY-SMITH, J. Community profiling: auditing social needs. Berkshire, UK: Open University Press, 1998.

HEDTKE, R. Who is afraid of a non-conformist youth? The right to dissent and to not participate. In: HEDKE, R.; ZIMENKOVA, T. Education for civic and political participation: a critical approach. Londres: Routledge, 2013. p. 54-78.

HUNTINGTON, S. How countries democratize. Political Science Quarterly, v. 106, n. 4, p. 579-616, 1992.

KELLETT, M. Rethinking children and research: attitudes in contemporary society. London: Continuum, 2010.

LIMA, L. C. A escola como organização educativa. São Paulo: Cortez, 2001.

LOVE, S.; BOXELAAR, L.; O’DONNELL, J.; FRANCIS, J. Community profiling: from technique to reflective practice in community engagement for natural resource management. The Journal of Agricultural Education and Extension, v. 13, n. 3, p. 177-189, 2007.

MCCOWAN, T. Rethinking citizenship education: a curriculum for participatory democracy. London: Continuum, 2009.

MENEZES, I. Desenvolvimento psicológico na formação pessoal e social. Porto: Asa, 1999.

MENEZES, I. Civic education in Portugal: curricular evolutions in basic education. Journal of Social Science Education, v. 2, p. 1-13, 2003.

MENEZES, I. Intervenção comunitária: uma perspetiva psicológica. Porto: Livpsic/ Legis Editora, 2010.

MENEZES, I.; AFONSO, M. R.; GIÃO, J.; AMARO, G. Conhecimentos, conceções e práticas de cidadania dos jovens portugueses: um estudo internacional. Lisboa: Direcção-Geral de Inovação e Desenvolvimento Curricular, 2005.

MÓNICA, M. Educação e sociedade no Portugal de Salazar: a escola primária salazarista 1926-1939. Lisboa: Editorial Presença, 1978. 
MONTEIRO, H.; FERREIRA, P. D. Unpolite citizenship: the non-place of conflict in political education. Journal of Social Science Education, v. 10, n. 4, p. 5-11, 2011.

NOVOA, A. L'Europe et l'éducation: éléments d'analyse socio-historique des politiques éducatives européennes. In: WINTHER-JENSEN, T. Challenges to European education: Cultural values, national identities, and global responsabilities. Sonderdruck: Peter Lang, 1996. p. 29-79.

OLDFATHER, P. Songs “come back most to them": students' experiences as researchers. Theory into Practice, v. 34, n. 2, p. 131-137, 1995.

OSLER, A.; STARKEY, H. Education for democratic citizenship: a review of research, policy and practice 1995-2005. Research Papers in Education, v. 21, n. 4, p. 433-466, 2006.

RIBEIRO, A. B.; RODRIGUES, M.; CAETANO, A.; PAIS, S.; MENEZES, I. Promoting 'active citizens'? The critical vision of NGOs over citizenship education as an educational priority across Europe. International Journal of Progressive Education, v. 8, n. 3, p. 32-47, 2012.

RODRIGUES, M. Diário de bordo: estudos de caso em quatro escolas públicas. Relatório do projeto EduCiPart, FPCEUP, 2012.

ROGOFF, B.; PARADISE, R.; ARAUZ, R. M.; CORREA-CHÁVEZ, M.; ANGELILLO, C. Firsthand learning through intent participation. Annual Review of Psychology, v. 54, n. 1, p. 175-203, 2003.

RUGET, V. The renewal of civic education in France and in America: comparative perspectives. The Social Science Journal, v. 43, n. 1, p. 19-34, 2006.

STOER, S. Educação e mudança social. Porto: Afrontamento, 1986.

TEATER, B.; BALDWIN, M. Exploring the learning experiences of students involved in community profiling projects. Social Work Education, v. 28, n. 7, p. 778-791, 2009.

TERHART, E. Constructivism and teaching: a new paradigm in general didactics? Journal of Curriculum Studies, v. 35, n. 1, p. 25-44, 2003.

VILLAVERDE CABRAL, M. Efeitos de classe e efeitos societais: elites e operariado ante a cidadania política numa perspetiva comparada europeia. In: VALA, J.; TORRES, A. Contextos e atitudes sociais na Europa. Lisboa: Instituto de Ciências Sociais, 2007. p. 37-67.

Texto recebido em 20 de maio de 2014

Texto aprovado em $1^{\circ}$ de julho de 2014. 
